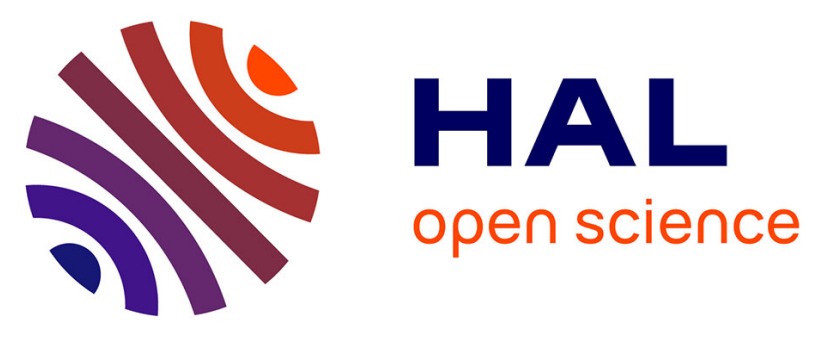

\title{
Speciation of Metals in Asphaltenes by High-Performance Thin-Layer Chromatography and Laser Ablation Inductively Coupled Plasma-Mass Spectrometry
}

Rémi Moulian, Sara Gutierrez Sama, Carole Garnier, Sandra Mounicou, Maxime Enrico, Xavier Jaurand, Ryszard Lobinski, Pierre Giusti, Brice Bouyssière, Caroline Barrère-Mangote

\section{- To cite this version:}

Rémi Moulian, Sara Gutierrez Sama, Carole Garnier, Sandra Mounicou, Maxime Enrico, et al.. Speciation of Metals in Asphaltenes by High-Performance Thin-Layer Chromatography and Laser Ablation Inductively Coupled Plasma-Mass Spectrometry. Energy \& Fuels, 2019, 33 (7), pp.6060-6068. 10.1021/acs.energyfuels.9b00676 . hal-02282550

HAL Id: hal-02282550

https://hal-univ-pau.archives-ouvertes.fr/hal-02282550

Submitted on 18 Jan 2022

HAL is a multi-disciplinary open access archive for the deposit and dissemination of scientific research documents, whether they are published or not. The documents may come from teaching and research institutions in France or abroad, or from public or private research centers.
L'archive ouverte pluridisciplinaire HAL, est destinée au dépôt et à la diffusion de documents scientifiques de niveau recherche, publiés ou non, émanant des établissements d'enseignement et de recherche français ou étrangers, des laboratoires publics ou privés. 


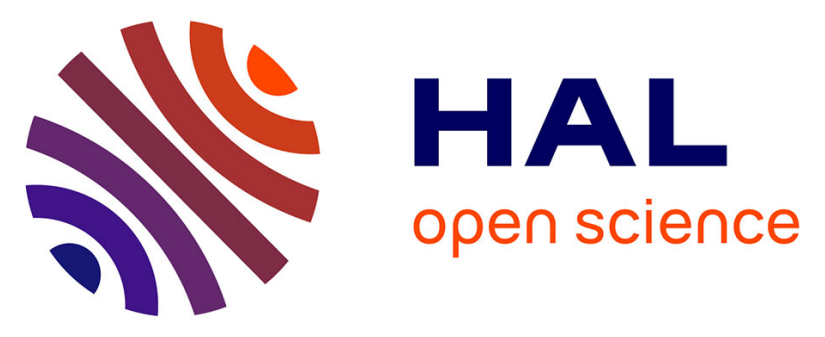

\section{Speciation of Metals in Asphaltenes by High-Performance Thin-Layer Chromatography and Laser Ablation Inductively Coupled Plasma-Mass Spectrometry}

Rémi Moulian, Sara Gutierrez Sama, Carole Garnier, Sandra Mounicou, Maxime Enrico, Xavier Jaurand, Ryszard Lobinski, Pierre Giusti, Brice Bouyssière, Caroline Barrère-Mangote

\section{- To cite this version:}

Rémi Moulian, Sara Gutierrez Sama, Carole Garnier, Sandra Mounicou, Maxime Enrico, et al.. Speciation of Metals in Asphaltenes by High-Performance Thin-Layer Chromatography and Laser Ablation Inductively Coupled Plasma-Mass Spectrometry. Energy and Fuels, American Chemical Society, 2019, 33, pp.6060 - 6068. 10.1021/acs.energyfuels.9b00676 . hal-03133582

\section{HAL Id: hal-03133582 \\ https://hal.archives-ouvertes.fr/hal-03133582}

Submitted on 6 Aug 2021

HAL is a multi-disciplinary open access archive for the deposit and dissemination of scientific research documents, whether they are published or not. The documents may come from teaching and research institutions in France or abroad, or from public or private research centers.
L'archive ouverte pluridisciplinaire HAL, est destinée au dépôt et à la diffusion de documents scientifiques de niveau recherche, publiés ou non, émanant des établissements d'enseignement et de recherche français ou étrangers, des laboratoires publics ou privés. 


\section{Speciation of Metals in Asphaltenes by High-}

\section{Performance Thin-Layer Chromatography and Laser}

\section{Ablation Inductively Coupled Plasma-Mass}

\section{Spectrometry}

Rémi Moulian ${ }^{a, b, c}$, Sara Gutierrez Sama ${ }^{a, b, c}$, Carole Garnier ${ }^{b}$, Sandra Mounicou ${ }^{a}$, Maxime

Enrico $^{a}$, Xavier Jaurand ${ }^{d}$, Ryszard Lobinsky ${ }^{a, c}$, Pierre Giusti ${ }^{b, c}$, Brice Bouyssiere ${ }^{a, c}$, Caroline

Barrère-Mangote ${ }^{b, c}$

${ }^{a}$ CNRS/ Univ pau \& pays ADOUR/ E2S UPPA, Institut des Sciences Analytiques et de Physico-

Chimie Pour L'environnement et les Materiaux, UMR5254, Helioparc- 2 Avenue du Président

Angot 64000, Pau, France

${ }^{b}$ TOTAL Refining and Chemicals, Total Research and Technologies Gonfreville, BP 27, 76700,

Harfleur, France

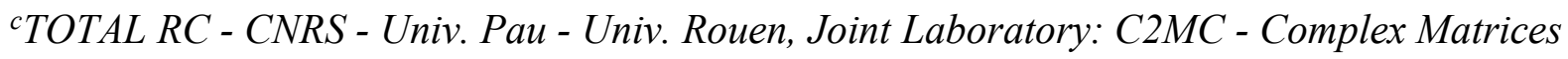

Molecular Characterization

${ }^{\mathrm{d}}$ Centre Technologique des Microstructures, Université Claude Bernard Lyon1, 5 rue Raphael

Dubois-Bâtiment Darwin B, F-69622, Villeurbanne Cedex, France 


\section{ABSTRACT}

Asphaltenes are considered the most problematic components of heavy oils because they can self-aggregate which leads to precipitation and causes various problems during oil recovery, transportation and refining. The contribution of the porphyrins present in asphaltenes to the aggregation cannot be studied by direct elementary analysis techniques since in this form, the porphyrins are complexed with metals. Thus, gel permeation chromatography inductively coupled plasma-mass spectrometry (GPC-ICP MS) has been used in previous studies. The results showed that the molecular weight of asphaltene aggregates could be increased by free metalcontaining porphyrins (corresponding to the lower molecular weight fraction) interacting with their surfaces by weak forces. The characterization of free porphyrins within the asphaltenes is therefore of great importance for understanding the mechanism of the aggregation, coprecipitation and demetallation processes. Here, we developed a method for the separation of free porphyrins from asphaltenes based on their polarity using high-performance thin-layer chromatography (HPTLC). This technique is particularly well suited for asphaltene analysis since it avoids stationary phase endangerment from clogging, as the plates are single use. Instead of classic Si-based sorbents, cellulose plates were used in this study. The lower polarity of their hydroxyl groups lead to less irreversible adsorption and improved detection for the ICP-MS. Two well-separated peaks were obtained from purified asphaltene (Asphaltene 2017 from the Petrophase congress interlaboratory study) and its corresponding whole crude oil and C5 and C7 fractions. The distribution of vanadium due to migration was determined by laser ablation (LA) ICP MS. The eluted fraction would contain the free porphyrins, whereas the fraction that remained at the application point (the major fraction) would corresponded to trapped porphyrins. 
Moreover, comparison with the signal obtained by UV densitometry would elucidated the ratio between the inorganic and organic material. 


\section{INTRODUCTION}

The composition of asphaltenes, the most polar fraction in a petroleum matrix, remains uncertain. Speight ${ }^{1}$ defined asphaltenes as the fraction that precipitates in the presence of alkanes but is soluble in hot toluene. The asphaltenes that precipitate in n-pentane, $n$-hexane and nheptane are referred to as $\mathrm{C} 5, \mathrm{C} 6$ and $\mathrm{C} 7$ asphaltenes, respectively. Asphaltenes contain a wide variety of molecules with different aromaticities, high polarities, and high contents of heteroatoms and metals $(\mathrm{Ni}, \mathrm{V} \ldots)^{2-4}$. These properties allow asphaltenes to self-aggregate in fairly concentrated solutions, leading to macroaggregation that results in precipitation in organic media. ${ }^{5-7}$ The nano and macroaggregation must be understood to avoid problematic effects, such as pipe clogging, and nanoaggregation may be linked to the efficiency in catalytic processes via pore size.

Thin-layer chromatography (TLC), usually with silica plates, has been extensively ${ }^{8-18}$ used for characterizing petroleum samples. For instance, Cebolla et al. ${ }^{8}$ used silica gel plates impregnated with berberine to separate SARA components (saturates, asphaltenes, resins, aromatics) of petroleum samples. Berberine is necessary to detect saturated compounds. ${ }^{8}$ Sharma et al. ${ }^{9}$ used TLC-FID (Iatroscan) to perform SARA separations with a standard deviation below $3.5 \%$. Furthermore, Jarne et al. ${ }^{10}$ used modified silica gel plates impregnated with caffeine to separate petroleum products according to their number of rings. Mateos et al. ${ }^{11}$ used silica gel plates impregnated with a solution of coralyne cation, which is more sensitive than berberine for many compounds. The use of TLC with single-use plates for asphaltene characterization can avoid the damage to chromatography columns caused by irreversible adsorption of the polar compounds present onto the stationary phase and asphaltene precipitation. Recently, Chacon-Patino et al. ${ }^{12}$ and Giraldo-Davila et al. ${ }^{13}$ used silica gel plates to separate asphaltene samples. They used a mix 
of $\mathrm{DCM} / \mathrm{MeOH}$ and then toluene to separate asphaltenes in three fractions. ${ }^{12,13}$ This technique can also be used on the preparative scale to separate fractions that can then be scratched, extracted with solvents, and further analyzed by other techniques, such as what was reported by Li et al. ${ }^{14}$. Vorapalawut et al. ${ }^{15}$ used TLC in conjunction with LA-ICP-MS for SARA separation with silica-based plates for the speciation of sulfur, vanadium and nickel from the SARA fractions of petroleum samples. Chirinos et al. ${ }^{16}$ also used this hyphenated technique for the rapid determination of the vanadium/nickel ratio in different samples of asphaltenes ${ }^{16}$. Although silica-based plates are typically used for HPTLC for hydrocarbon-type analyses, these plates are the most affected by irreversible adsorption at the application point due to the high polarity of the silanol groups present, and this effect is most dramatic in asphaltene analysis. The use of less polar sorbents, such as cellulose, could allow a more robust speciation of asphaltene. The use of sorbents that are not based on silica could facilitate the detection of certain analyte molecules by eliminating the high silica signal derived from the plate in LA-ICP-MS. Several authors have used TLC for the separation of porphyrins and metalloporphyrins. In 1978, Hajibrahim et al. ${ }^{17}$ used preparative TLC for the separation of carotenoids and porphyrins for further analysis. In 1989, Van Berkel et al. ${ }^{18}$ used liquid chromatography to obtain vanadyl porphyrin- and nickel porphyrin-enriched fractions from bitumen samples. Then, they used TLC with silica-based plates to separate the different porphyrins in each of the previous fraction. All the Ni porphyrins eluted with heptane/DCM 3/2\%v/v, while vanadyl porphyrins need a more polar solvent, such as $100 \%$ DCM.

The present study aims to first test the use of cellulose-based HPTLC plates for asphaltene speciation and compare the results to those achieved with classic silica-based plates. The efficiency of the method for separating free porphyrins from aggregates will be assessed by the 
analysis of samples previously separated by GPC. ${ }^{19,20,21}$ GPC is a widely used technique for the characterization of petroleum samples due to its ability to separate compounds by their hydrodynamic volume, molecular size and/or aggregation state. This separation strategy is relatively orthogonal to the polarity-based separation usually achieved on silica stationary phases. Deelchand et $a .^{22}$ thus proposed an off-line hyphenation of TLC and GPC techniques involving a preparative TLC separation of petroleum residue and pitch on silica-based plates followed by characterization of the fractions by UV, mass spectrometry and GPC. They obtained lower molecular weights and higher mobilities on the plates. Similar results were obtained by the same group for other samples. ${ }^{15}$

In this work, high-performance (HP) TLC will be used for the speciation of asphaltenes, particularly for the separation and detection of "free porphyrins." The porphyrins will be detected by elementary techniques, such as laser ablation-inductively coupled plasma-mass spectrometry (LA-ICP-MS) and UV densitometry. Most of the vanadium and nickel ions in asphaltenes are part of porphyrin complexes (tetrapyrrolic complexes mainly of vanadyl $\left(\mathrm{VO}^{2+}\right)$ and nickel (II) ions). ${ }^{23}$ Although porphyrins can be free in solution, they can also be trapped into nanoaggregates of asphaltenes, making them difficult to separate and analyze with UV-visible techniques. ${ }^{23,24}$ Improving the understanding the porphyrins's role associated with asphaltene nanoaggregates by different types of interactions ${ }^{25,26}$ in the aggregation process is the main objective of this study. For this purpose, our newly developed method using GPC and HPTLC characterization will be applied to different asphaltene samples obtained from the same crude oil with different alkanes, as well as to the Asphaltene 2017 reference sample. 


\section{EXPERIMENTAL SECTION}

Samples, Materials and Reagents. Samples. Asphaltene 2017 (from a middle east crude oil) from the interlaboratory study of the Petrophase congress was studied, and this sample contains $640 \mathrm{ppm}$ vanadium, and its preparative GPC fractions, ${ }^{20}$ asphaltenes $\mathrm{C} 5$ and $\mathrm{C} 7$, were also analyzed following the same methodology. Asphaltene 2017 is obtained first by ASTM D656012 method and after it was washed in soxhlet with heptane during 5 hours. This step is repeated until the material extracted from asphaltene is below $0.2 \mathrm{mg} / 200 \mathrm{~mL}$ heptane. Two reference molecules $(5,10,15,20$-tetraphenyl-21H,23H-vanadyl porphyrin and 5,10,15,20-tetraphenyl-21H23H-porphine nickel, purity 95 \%, Merck, Frankfurter Strasse 250 Darmstadt, 64293, Germany) were used.

Solvents. Tetrahydrofuran (THF, HPLC grade, without stabilizer, Lichrosolv, Merck, Frankfurter Strasse 250 Darmstadt, 64293, Germany) was used as the solvent for sample preparation. To facilitate the release of porphyrins, the solutions of the whole asphaltenic samples were subjected to ultrasound for $1 \mathrm{~h}$ to. Dichloromethane (DCM) and methanol (MeOH) (HPLC grade, Lichrosolv, Merck, Frankfurter Strasse 250 Darmstadt, 64293, Germany) were used to develop the HPTLC plates. Toluene, heptane and pentane were used to prepare Asphaltenes 2017, C7 and C5.

HPTLC Plates. Classic HPTLC silica gel plates (Merck, thickness: 0.15 -0.2 mm Frankfurter Strasse 250 Darmstadt, 64293, Germany) and cellulose HPTLC glass plates (Merck, thickness 0.15-0.2 mm, Frankfurter Strasse 250 Darmstadt, 64293, Germany), $20 \mathrm{~cm}$ x $10 \mathrm{~cm}$, without fluorescent indicators were used. The cellulose stationary phase is thinner and contains smaller, more uniform particles than silica gel for faster separation, better separation efficiency, better resolution, and more sensitive detection. ${ }^{27}$ 
Instrumentation. HPTLC. The HPTLC procedure was carried out with the following instrumentation from Camag. The sample application and sample development were performed using an Automatic TLC Sampler 4 (ATS4) and an Automated Multiple Development 2 (AMD2), respectively. UV absorbance chromatograms were monitored at a wavelength of 280 nm with a D2 \& W lamp by a TLC scanner. UV spectra from $190 \mathrm{~nm}$ to $900 \mathrm{~nm}$ were obtained using the same device. Finally, a TLC visualizer was used to obtain a picture of the plate under $366 \mathrm{~nm}$ UV light after development. Peak area data were collected using WinCATS software. HPTLC plates were cleaned with DCM and THF and dried at $110^{\circ} \mathrm{C}$ for 10 min prior to sample deposition. The samples were deposited $10 \mathrm{~mm}$ from the bottom of the plate. A highstrength mobile phase (DCM:MeOH, 99.5:0.5) was used to completely elute the free porphyrins, so they could be characterized separately from the rest of the material. The plate was developed in a single step until the solvent front reached $50 \mathrm{~mm} .^{28}$

The nickel and vanadyl porphyrins were calibrated by depositing six different amounts of the complexes; from 0.00537 to $1.08 \mu \mathrm{g}$ for vanadyl porphyrins and from 0.0054 to $1.08 \mu \mathrm{g}$ for nickel porphyrins. Furthermore, three different amounts of Asphaltene 2017, C5 and C7 (1 $\mu \mathrm{g}, 3$ $\mu \mathrm{g}$ and $5 \mu \mathrm{g}$ ) were deposited. The calibration standards and the samples were deposited on three cellulose plates for repeatability and on a silica plate for comparison. The repeatability of the method was calculated, and the differences between silica and cellulose were determined.

Additionally, Asphaltene $2017(1,2.5$ and $5 \mu \mathrm{g})$ and its GPC fractions (1, 2.5 and $5 \mu \mathrm{g})$ were deposited on another cellulose plate.

LA-ICP MS. Elementary analysis of the developed HPTLC plate was carried out by LA-ICP MS using a New Wave Research UP-213 Nd:YAG laser (ESI, Fremont, CA, USA, 48660 Kato Road, CA 94538, USA) coupled with ICP MS (7700 series, Agilent, 5301 Stevens Creek Blvd, 
Santa Clara, CA 95051, United States) under the operating conditions given in Table 1. The instrument was equipped with a Fassel-type quartz torch shielded with a grounded Pt electrode and a quartz bonnet. A standard quartz injector (1.75 $\mathrm{mm}$ i.d.) was used. An ablation chamber was installed on a three-axis translation stage and coupled to the ICP torch using a $60 \mathrm{~cm}$ Tygon tube (5.0 $\mathrm{mm}$ i.d.). The ablated material was swept by the carrier gas (helium) and mixed with the spectrometer makeup gas (argon) prior to introduction into the plasma. Ni sampler (orifice diameter $1.1 \mathrm{~mm}$ ) and skimmer (orifice diameter $0.8 \mathrm{~mm}$ ) cones were used. ${ }^{15}$ The laser beam followed a linear trajectory throughout the migration. The distribution of ${ }^{51} \mathrm{~V}$ compounds was controlled. To fit within the ablation cell, plates were cut to dimensions of 9x10 cm. FIJI ${ }^{29,30}$ image processing software was used to precisely determine the area of each spot of sample on the solvent front and normalize all the results obtained by UV and LA-ICP MS.

Preparative GPC. Fractionation was carried out following the method of Putman et al. ${ }^{20}$ Briefly, we used three Shodex (Showa Denko K. K., Japan) polystyrene-divinylbenzene (PS/DVB) preparative gel permeation columns (20 mm i.d., $300 \mathrm{~mm}$ length): KF2001 (particle size: $6 \mu \mathrm{m}$, exclusion limit: 1,500 Da), KF2002.5 (particle size: $6 \mu \mathrm{m}$, exclusion limit: 20,000 Da) and KF2004 (particle size: $7 \mu \mathrm{m}$, exclusion limit: 400,000 Da) connected in series with a KF-LG precolumn for protection. The column temperature was not controlled.

The preparative GPC system was calibrated with nine polystyrene standards with Mw values ranging from 630 to 2350000 Da using a refractive index detector. The equation of the mass calibration curve was as follows: $\log (\mathrm{Mw})=-1.10^{-5} \mathrm{x}^{3}+0.0048 \mathrm{x}^{2}-0.7188 \mathrm{x}+40.614(\mathrm{R}>$ 0.9988), where $\mathrm{x}$ is the elution volume.

One milliliter of the asphaltene solution diluted 100 times in THF (Sigma-Aldrich) was injected into the column by an injection loop connected to an external 6-way valve. Xylene was 
used as the mobile phase instead of THF, and the eluent was delivered at a flow rate of $3 \mathrm{~mL} / \mathrm{min}$ by a Dionex high-performance liquid chromatography (HPLC) system with an UltiMate 3000 microflow pump.

Fractions of different molecular weights were collected at the outlet of the preparative columns, and the fractions contained the high-molecular-weight aggregates (HMW), mediummolecular-weight (MMW) compounds, low-molecular-weight (LMW) compounds, and the tailing fraction of compounds retained on the stationary phase. The peak corresponding to the porphyrinic solution was observed in the LMW fraction; thus, the free porphyrins are expected to be present in this fraction.

\section{RESULTS AND DISCUSSION}

Reference Metalloporphyrins. As shown by Chirinos et al., ${ }^{16}$ to obtain sufficient LA-ICPMS signals on classic Si-based plates, several tens of $\mu \mathrm{g}$ of crude oil is typically deposited. This amount of sample does not allow good quality migrations in HPTLC because of the thin layer of sorbent (approximately $100 \mu \mathrm{m}$ vs $250 \mu \mathrm{m}$ for classic $\mathrm{TLC}^{15,16}$ ). Cellulose plates could represent an interesting alternative for achieving suitable migration. Indeed, unlike silica, cellulose is a polar sorbent with alcohol and ether functionalities that is suitable for adsorption chromatography. Moreover, the use of cellulose plates improve the detection in ICP MS by removing the intense silica interferences and plasma destabilization. Figure 1 compares silicaand cellulose-based HPTLC plates with $1 \mu \mathrm{g}$ of each reference vanadyl and nickel porphyrin deposited. The detections were carried out by LA-ICP MS. The ${ }^{51} \mathrm{~V}$ signal intensities from the two kinds of HPTLC plates differed by a factor of 10 (Figure 1a). As expected, vanadyl porphyrins quantitatively elute at the solvent front on the cellulose plate (black line). In comparison, only $72 \%$ of these species migrate with the solvent front (red line) on silica-based 
plates, indicating that a significant fraction remained at the application point. Similar results were obtained for nickel porphyrins (Figure 1b). Our observations confirm that cellulose interacts less with the porphyrin samples than does the silica gel. We strongly suspect that from the chromatographic point of view, the separation of the components is the result of their different solubilities in the solvent. Moreover, the ${ }^{58} \mathrm{Ni}$ LA-ICP MS signal is half as intense as the vanadium signal ( $\mathrm{V}$ has a lower ionization potential $(6,7)$ than $\mathrm{Ni}(7,6)$ and thus has a better detection limit in ICP MS).

This unexpected retention of porphyrins at the application point could be due to irreversible adsorption, as previously observed in our laboratory for polar compounds on silica plates. Several authors have reported the degradation of metalloporphyrins on silica-based TLC plates, but degradation preferentially occurred for Ni porphyrins, as shown by Ali et al. ${ }^{31}$ and Van Berkel et al. ${ }^{18}$. To better understand this phenomenon, UV-Vis densitometry spectra were recorded directly at the application point and at the solvent front on the two plates (Figure 2). Even when the UV spectra were recorded from the solid HPTLC plate rather than in the solution, the expected absorption bands for the porphyrins were observed in the spectra of the eluted fractions on the plates with a large Soret band at approximately $425 \mathrm{~nm}$ (gray band), a $\beta$ band at approximately $545 \mathrm{~nm}$ and an $\alpha$ band at approximately $575 \mathrm{~nm}$ (Figure 2 (a, b vertical black lines)). The wavelengths of the maximum intensities of these bands were close to those reported by Freeman et al. ${ }^{32}$ for benzo vanadyl porphyrins. The spectra obtained from the noneluted fractions on the plates are shown in Figure 2 ( $\mathrm{a}, \mathrm{b}$ red lines). The spectrum obtained from the cellulose plate has more noise, and no characteristic absorption bands indicating that the vanadium porphyrin complexes remained at the application point were observed. In contrast, the spectrum obtained at the application point from the silica-based plate is similar to those obtained 
for the porphyrins at the elution front, suggesting that a portion of this analyte is definitely adsorbed at the application point. Futhermore, on cellulose plate Figure 3 (c), UV signal (red line) at the deposition point equal only $1 \%$ of the total signal instead of for ${ }^{51} \mathrm{~V}$ signal for LAICP-MS (black line) the signal at the deposition point equal to $6 \%$ to the total. It would mean that there is $6 \%$ of the vanadium at the application point but the one is not inside a porphyrin. On the Figure 2 (d), contrary to the cellulose there is more signal for the UV at the application point than for LA-ICP-MS.

Vanadium calibration on the cellulose plate showed that the reference porphyrin moved with the front solvent (Figure 3). This plate was analyzed by LA-ICP MS, but the size of the eluted spot from the different migration trials and on different plates differed because the spot spread out. To solve this issue, we used image processing software (FIJI) to determine the area of each spot of the eluted and noneluted fractions. The laser-ablated area together with ICP MS signal data allows correction of the data (supporting information Figure S1). FIJI was used for the treatment of all the plates.

The calibration curve obtained for vanadyl porphyrin (shown in Figure 3b) has the equation $\mathrm{Y}=210^{\wedge} 8 \mathrm{x}\left( \pm 5.510^{\wedge} 6\right)$ with $\mathrm{R}^{2}=0.994$ and $\mathrm{F}=1325$. This calibration curve was prepared on a single cellulose plate. The results of the interplate repeatability are given in Table 2, and these results indicate that the relative standard deviation from one plate to another could be up to $25 \%$, probably resulting from differences in migration and plate quality. For this reason, calibration points were added to each plate (A, B and C) and were used to calibrate the quantification data.

GPC Fractions of Asphaltene 2017. Our previous work ${ }^{19}$ using GPC showed that heavy petroleum samples could be separated into four fractions, referred to as the high-molecularweight (HMW), medium-molecular-weight (MMW), low-molecular-weight (LMW) and tailing 
for analytes having interactions with the stationary phase (unexpected separation mechanism in GPC), as proposed in Figure 4. Note that by GPC-ICP-MS, our reference vanadyl porphyrins lead to a sharp peak in the LMW area, ${ }^{19,21}$ as shown in Figure 4.

A 1-mL aliquot of Asphaltene 2017 diluted in THF was fractionated according to this method. The obtained chromatogram is shown in Figure 4, and the corresponding mass balance is given in Table 3. There is no correlation between the mass of the fraction and quantity of vanadium, and most of the metal species and total material are part of the HMW fraction. However, the \% of vanadium in the LMW fraction is higher than the $\%$ of total material in this fraction.

The different GPC fractions were deposited on HPTLC cellulose plates and developed using the same procedure as was used for the porphyrins. The plates were analyzed by LA-ICP MS and by UV densitometry at $280 \mathrm{~nm}$. A picture of the plate and the LA-ICP MS chromatograms are given in Figure 5, and the various measured areas are given Table 4. Figure 5 shows that for all GPC fractions, a portion of the sample remains at the application point and a portion migrates with the solvent front. Surprisingly, even for the LMW fraction, which is considered the free porphyrin part of the sample, $65 \%$ of the vanadium remain at the application point, as indicated in Table 4. This result means that the LMW fraction is not only made of porphyrins similar to our porphyrins standards and that these porphyrins are more polar (polar side chains) or they can reaggregate. However, Deelchand et al. ${ }^{22}$ observed the same trend; higher molecular weight fractions show lower mobilities on the HPTLC plate.

We can also follow the ratio between LA and UV (Table 4). For the MMW, LMW fractions of Asphaltene 2017, the ratio of eluted part LA/UV is between 600 and 800 . However, the ratio is approximately 300 for the HMW fraction. Thus, the eluted MMW and LMW fractions are more concentrated in vanadium than is HMW. 
An UV-Vis spectrum for each peak was recorded to obtain structural information on the molecules present, and the spectra are given Figure 6. The spectrum obtained for the noneluted part, drawn in red, is similar for each fraction. This spectrum, with a maximum intensity at approximately $240 \mathrm{~nm}$ that decreases continuously until $800 \mathrm{~nm}$, is characteristic of highly polyaromatic compounds. These spectra are similar to those obtained by Bonoldi et al. ${ }^{33}$ for an asphaltene diluted in THF. However, unlike the work of Bonoldi et al. ${ }^{33}$, no peaks were observed at approximately $400 \mathrm{~nm}$, which is the wavelength of the porphyrin Soret band, whereas large peaks were observed in LA-ICP-MS at the application point, indicating the presence of vanadium. As proposed by Evdokimov et al., ${ }^{24}$ this could be due to the occlusion of porphyrins inside the aggregates, which would prevent the detection of their characteristic UV-Vis absorption bands. Furthermore, the spectra obtained from the eluted parts (black line) differed depending on the fraction. For the HMW fraction (Figure 6), the signal between $300 \mathrm{~nm}$ and 400 $\mathrm{nm}$ is weaker. For the MMW, LMW and T fractions, we can see the Soret band of the porphyrins at $420 \mathrm{~nm}$, especially for the LMW fraction (represented by a star). This result suggests that separation by HPTLC allows the isolation of the free porphyrins contained in the MMW, LMW and $\mathrm{T}$ fractions from the rest of the material.

Asphaltenes 2017, C7 and C5. The distribution of the ${ }^{51} \mathrm{~V}$ species in Asphaltene 2017, Asphaltene C7 and Asphaltene C5 was controlled using the same methodology, and the distributions are given in Figure 7 and Table 5. As shown in Figure 7, again only two peaks were observed. The fraction of the asphaltene with the greatest affinity for the plate has a higher vanadium content than the eluted fraction (Table 5), meaning that the largest portion of the metal would be in the aggregates. Table 5 shows that the ratios between LA/UV for the application point of asphaltene varied. For asphaltene $\mathrm{C} 7$ and 2017 is close to 1800 . This would mean that 
the molecules removed during the washing do not stay at the application point or are not aromatics (as UV mostly detect aromatic compounds). Therefore, for asphaltene C5, the ratio is close to 1300, this would mean that in Asphaltene C5 there is more organic aromatic matter than in the others asphaltenes. For the eluted part, the ratio between LA/UV for asphaltene 2017 is close to 900 instead of 500 for C5 and C7. This would mean that precipitate asphaltene with C7 and wash it allow a better migration of metallic compounds.

The calibration curves shown in Table 2 were used to calculate the concentrations of vanadium in Asphaltene 2017, C5, and C7 (supporting information Table S1). The average concentration on the three different plates with three different depositions was approximately $642 \mathrm{ppm}$, which is in good agreement with the concentration obtained by the ATSM method (640 ppm). Thus, HPTLC-LA-ICP-MS with a cellulose plate allowed us to calculate the concentration of vanadium in the asphaltene sample. According to the results, the concentration in Asphaltene C7 is close to that in Asphaltene 2017, which has an average of $611 \mathrm{ppm}$ vanadium. However, Asphaltene C5 is less concentrated (464 ppm), meaning that during the precipitation of asphaltene, heptane promotes more coprecipitation of metals than nonmetallic compounds.

\section{CONCLUSIONS}

In this work, instead of classic Si-based sorbents, cellulose plates were used for HPTLC analysis of petroleum samples. Cellulose gives more intense signals (X10) with less noise than silica gel when the plates are analyzed by LA-ICP MS and allows the quantification of vanadium in asphaltene samples. Two well-separated peaks were obtained for purified asphaltene (Asphaltene 2017 from the Petrophase congress interlaboratory study) and its corresponding fractions. The eluted fraction was found to contain free porphyrins, whereas the fraction that 
remained at the application point (the major fraction) corresponded to trapped or highly polar porphyrins and was the most difficult part to remove. These results suggest that this separation could be used to pilot efficiently processes using hydrodemetallation step. Moreover, the differences between Asphaltene 2017, C7 and C5 can be determined by comparing their UV and LA-ICP MS data as a function of the nature of the asphaltene. The concentration in vanadium is higher in asphaltene precipitated with heptane, and there is less organic matter in Asphaltene 2017 (more washed).

\section{ASSOCIATED CONTENT}

\section{Supporting Information}

Figure S1. Processing data with FIJI

Table S1. Concentration obtained by HPTLC-LA-ICP-MS after Image Processing

\section{AUTHOR INFORMATION}

\section{Corresponding Author}

Tel: +33 (0) 235551102

Email: caroline.mangote@total.com

Tel: +33 (0) 559407752

Email: brice.bouyssiere@univ-pau.fr

\section{Notes}


The authors declare no competing financial interest

\section{ACKNOWLEDGMENT}

This work was supported by Conseil Régional d'Aquitaine (20071303002PFM) and FEDER (31486/08011464). The authors thank TOTAL for supplying the oil samples. 


\section{REFERENCES}

(1) Speight, J. G. Petroleum asphaltenes - Part 1: asphaltenes, resins and the structure of petroleum. Oil Gas Sci. Technol. 2004, 59, 467-477.

(2) Strausz, O. P.; Peng, P. A.; Murgich, J. About the colloidal nature of asphaltenes and the MW of covalent monomeric units. Energy Fuels 2002, 16, 809-822.

(3) Leyva, C.; Ancheyta, J.; Berrueco, C.; Millán, M. Chemical characterization of asphaltenes from various crude oils. Fuel Process. Technol. 2013, 106, 734-738.

(4) Pereira, T. M. C.; Vanini, G.; Oliveira, E. C. S.; Cardoso, F. M. R.; Fleming, F. P.; Neto, A. C.; Lacerda, V.; Castro, E. V. R.; Vaz, B. G.; Romão, W. An evaluation of the aromaticity of asphaltenes using atmospheric pressure photoionization Fourier transform ion cyclotron resonance mass spectrometry - APPI(土)FT-ICR MS. Fuel 2014, 118, 348-357.

(5) McKenna, A. M.; Marshall, A. G.; Rodgers, R. P. Heavy petroleum composition. 4. Asphaltene compositional space. Energy Fuels 2013, 27, 1257-1267.

(6) Barrera, D. M.; Ortiz, D. P.; Yarranton, H. W. Molecular weight and density distributions of asphaltenes from crude oils. Energy Fuels 2013, 27, 2474-2487.

(7) Yarranton, H. W.; Ortiz, D. P.; Barrera, D. M.; Baydak, E. N.; Barré, L.; Frot, D.; Eyssautier, J.; Zeng, H.; Xu, Z.; Dechaine, G.; Becerra, M.; Shaw, J. M.; McKenna, A. M.; Mapolelo, M. M.; Bohne, C.; Yang, Z.; Oake, J. On the size distribution of self-associated asphaltenes. Energy Fuels 2013, 27, 5083-5106. 
(8) Cebolla, V. L.; Membrado, L.; Domingo, M. P.; Henrion, P.; Garriga, R.; González, P.; Cossío, F. P.; Arrieta, A.; Vela, J. Quantitative applications of fluorescence and ultraviolet scanning densitometry for compositional analysis of petroleum products in thin-layer chromatography. J. Chromatogr. Sci. 1999, 37, 219-226.

(9) Sharma, B. K.; Sarowha, S. L. S.; Bhagat, S. D.; Tiwari, R. K.; Gupta, S. K.; Venkataramani, P. S. Hydrocarbon group type analysis of petroleum heavy fractions using the TLC-FID technique. Fresenius J. Anal. Chem. 1998, 360, 539-544.

(10) Jarne, C.; Cebolla, V. L.; Membrado, L.; Le Mapihan, K.; Giusti, P. High-performance thin-layer chromatography using automated multiple development for the separation of heavy petroleum products according to their number of aromatic rings. Energy Fuels 2011, 25, 45864594.

(11) Mateos, E.; Cebolla, V. L.; Membrado, L.; Vela, J.; Galvez, E. M.; Matt, M.; Cossio, F. P. Coralyne cation, a fluorescent probe for general detection in planar chromatography. $J$. Chromatogr. A 2007, 1146, 251-257.

(12) Chacón-Patiño, M. L.; Blanco-Tirado, C.; Orrego-Ruiz, J. A.; Gómez-Escudero, A.; Combariza, M. Y. High resolution mass spectrometric view of asphaltene- $\mathrm{SiO}_{2}$ interactions. Energy Fuels 2015, 29, 1323-1331.

(13) Giraldo-Dávila, D.; Chacón-Patiño, M. L.; McKenna, A. M.; Blanco-Tirado, C.; Combariza, M. Y. Correlations between molecular composition and adsorption, aggregation, and emulsifying behaviors of petrophase 2017 asphaltenes and their thin-layer chromatography fractions. Energy Fuels 2016, 32, 2769-2780. 
(14) Li, W.; Morgan, T. J.; Herod, A. A.; Kandiyoti, R. Thin-layer chromatography of pitch and a petroleum vacuum residue. Relation between mobility and molecular size shown by sizeexclusion chromatography. J. Chromatogr. A 2004, 1024, 227-243.

(15) Vorapalawut, N.; Labrador, M. M.; Pohl, P.; Caetano, M.; Chirinos, J.; Arnaudguilhem, C.; Bouyssiere, B.; Shiowatana, J.; Lobinski, R. Application of TLC and LA ICP SF MS for speciation of S, Ni and V in petroleum samples. Talanta 2012, 97, 574-578.

(16) Chirinos, J.; Oropeza, D.; González, J.; Ranaudo, M.; Russo, R. E. Determination of Vanadium/Nickel proportionality in the asphaltene fraction of crude oil using thin-layer chromatography with femtosecond laser ablation-inductively coupled plasma-mass spectrometry. Energy Fuels 2013, 27, 2431-2436.

(17) Hajibrahim, S. K.; Tibbetts, P. J. C.; Watts, C. D.; Maxwell, J. R.; Eglinton, G.; Colin, H.; Guiochon, G. Analysis of carotenoid and porphyrin pigments of geochemical interest by high-performance liquid chromatography. Anal. Chem. 1978, 50, 549-553.

(18) Van Berkel, G. J.; Quirke, J. M. E.; Filby, R. H. The Henryville Bed of the New Albany shale-I. Preliminary characterization of the Nickel and Vanadyl porphyrins in the bitumen. Org. Geochem. 1989, 14, 119-128.

(19) Sama, S. G.; Desprez, A.; Krier, G.; Lienemann, C.-P.; Barbier, J.; Lobinski, R.; BarrereMangote, C.; Giusti, P.; Bouyssiere, B. Study of the aggregation of metal complexes with asphaltenes using gel permeation chromatography inductively coupled plasma high-resolution mass spectrometry. Energy Fuels 2016, 30, 6907-6912. 
(20) Putman, J. C.; Gutiérrez Sama, S.; Barrère-Mangote, C.; Rodgers, R. P.; Lobinski, R.; Marshall, A. G.; Bouyssière, B.; Giusti, P. Analysis of petroleum products by gel permeation chromatography coupled online with inductively coupled plasma mass spectrometry and offline with fourier transform ion cyclotron resonance mass spectrometry. Energy Fuels 2018. DOI: 10.1021/acs.energyfuels.8b02788

(21) Desprez, A. Caractérisation moléculaire et élémentaire des produits pétroliers lourds. Ph.D. Thesis, University of Pau, Pau, France, 2014.

(22) Deelchand, J. P.; Naqvi, Z.; Dubau, C.; Shearman, J.; Lazaro, M. J.; Herod, A. A.; Read, H.; Kandiyoti, R. Planar chromatographic separation of petroleum residues and coal-derived liquids. J. Chromatogr. A 1999, 830, 397-414.

(23) Zhao, X.; Xu, C.; Shi, Q. Porphyrins in heavy petroleums: a review. In: Structure and Modeling of Complex Petroleum Mixtures; Xu, C.; Shi, Q., Eds.; Cham: Springer International Publishing; 2016. pp. 39-70.

(24) Evdokimov, I. N.; Fesan, A. A.; Losev, A. P. Occlusion of foreign molecules in primary asphaltene aggregates from near-UV-visible absorption studies. Energy Fuels 2017, 31, 13701375.

(25) Caumette, G.; Lienemann, C.-P.; Merdrignac, I.; Bouyssiere, B.; Lobinski, R. Element speciation analysis of petroleum and related materials. J. Anal. At. Spectrom. 2009, 24, 263-276.

(26) Barrow, M. P.; McDonnell, L. A.; Feng, X.; Walker, J.; Derrick, P. J. Determination of the nature of naphthenic acids present in crude oils using nanospray fourier transform ion 
cyclotron resonance mass spectrometry: the continued battle against corrosion. Anal. Chem. 2003, 75, 860-866.

(27) Striegel, M. F.; Hill, J. Thin-layer Chromatography for Binding Media Analysis. Getty Conservation Institute: Los Angeles, CA, 1996.

(28) Poole, C. F.; Dias, N. C. Practitioner's guide to method development in thin-layer chromatography. J. Chromatogr. A 2000, 892, 123-142.

(29) Rueden, C.T., Schindelin, J., Hiner, M.C., B.E., Walter, A.E., Arena, E.T., Eliceiri, K.W. ImageJ2: ImageJ for the next generation of scientific image data. BMC Bioinformatics 2017, 18:529, PMID 29187165.

(30) Schindelin, J., Arganda-Carreras, I., Frise, E., Kaying, V., Longair, M., Pietzsch, T., Preibisch, S., et al. Fiji: An open source platform for biological image analysis. Nature Methods 2012, 9(7), 676-682, PMID 22743772.

(31) Ali, M. F.; Perzanowski, H.; Bukhari, A.; Al-Haji, A. A. Nickel and vanadyl porphyrins in Saudi Arabian crude oils. Energy Fuels 1993, 7, 179-184.

(32) Freeman, D. H.; Saint Martin, D. C.; Boreham, C. J. Identification of metalloporphyrins by third-derivative UV/VIS diode array spectroscopy. Energy Fuels 1993, 7, 194-199.

(33) Bonoldi, L.; Flego, C.; Galasso, L. Beyond the average molecule description of asphaltenes: hyphenated gel permeation chromatography and spectroscopic analyses. Energy Fuels 2016, 30, 3630-3636. 


\section{TABLES}

Table 1. LA-ICP MS Operating Parameters

\begin{tabular}{|c|c|}
\hline \multicolumn{2}{|l|}{ Agilent 7700 series ICP MS } \\
\hline $\begin{array}{l}\text { Plasma Ar gas flow rate } \\
\left(\text { L.min }^{-1}\right)\end{array}$ & 15 \\
\hline $\begin{array}{l}\text { Auxiliary Ar gas flow rate } \\
\left(\text { L.min }{ }^{-1}\right)\end{array}$ & 1 \\
\hline Measured Isotope & $\begin{array}{l}{ }^{13} \mathrm{C}, \quad{ }^{32} \mathrm{~S}, \quad{ }^{51} \mathrm{~V}, \quad{ }^{58} \mathrm{Ni}, \\
{ }^{60} \mathrm{Ni}\end{array}$ \\
\hline Analysis time (s) & 506 \\
\hline \multicolumn{2}{|l|}{ New Wave Research UP-213 LA } \\
\hline Wavelength (nm) & 213 \\
\hline Pulse energy (mJ) & $0.45(50 \%)$ \\
\hline Fluence $\left({\left.\mathrm{J} . \mathrm{cm}^{-2}\right)}^{-}\right.$ & 3.5 \\
\hline Spot size $(\mu \mathrm{m})$ & 200 \\
\hline Repetition rate $(\mathrm{Hz})$ & 20 \\
\hline Scan speed $\left(\mu . \mathrm{ms}^{-1}\right)$ & 100 \\
\hline $\begin{array}{l}\text { Carrier He gas flow rate } \\
\left({\left.\mathrm{L} . \mathrm{min}^{-1}\right)}^{-}\right.\end{array}$ & 0.5 \\
\hline
\end{tabular}


Table 2. Calibration with Vanadyl Porphyrins

\begin{tabular}{lrrrrr}
\hline $\begin{array}{l}\text { Vanadium } \\
(\mu \mathrm{g})\end{array}$ & \multicolumn{1}{l}{ Area A } & \multicolumn{1}{c}{ Area B } & Area C & Average & $\begin{array}{r}\text { Standard } \\
\text { deviation } \\
(\%)\end{array}$ \\
\hline 0.00537 & 524,304 & 676,552 & 706,549 & 635,802 & 15 \\
0.0108 & $1,456,995$ & $1,404,246$ & 896,046 & $1,252,429$ & 24 \\
0.0537 & $7,797,726$ & $7,976,937$ & $6,050,314$ & $7,274,992$ & 14 \\
0.108 & $13,860,441$ & $16,379,744$ & $12,440,338$ & $14,226,841$ & 14 \\
0.537 & $118,697,108$ & $162,436,773$ & $108,242,613$ & $129,792,165$ & 22 \\
1.08 & $209,863,919$ & $231,665,273$ & $169,634,752$ & $203,721,315$ & 15 \\
\hline
\end{tabular}


Table 3. Mass Balance of Asphaltene 2017 and ${ }^{51} \mathrm{~V}$ Repartition in the Collected GPC Fractions Obtained by GPC-ICP-MS

\begin{tabular}{lcrrrrr}
\hline & $\begin{array}{c}\text { Injected } \\
\text { Quantity }\end{array}$ & HMW & MMW & LMW & Tailing & Recovery \\
\hline $\begin{array}{l}\text { Mass of Asphaltene } \\
2017 \text { (mg) }\end{array}$ & 9.0 & 4.8 & 2.3 & 0.9 & 0.2 & 8.2 \\
$\begin{array}{l}\text { Mass of Asphaltene } \\
\begin{array}{l}2017(\%) \\
\text { Vanadium by GPC- }\end{array}\end{array}$ & 53.3 & 25.6 & 10.0 & 2.2 & 91.1 \\
ICP-MS (\%) & 52.3 & 26.9 & 15.0 & 5.8 & 100 \\
\hline
\end{tabular}


Table 4. Area and Percentages of Noneluted and Eluted Material from $1 \mu \mathrm{g}$ of Each Fraction for UV and ${ }^{51} \mathrm{~V}$ by LA-ICP-MS After Image Processing

\begin{tabular}{|c|c|c|c|c|c|c|c|}
\hline \multirow[b]{2}{*}{ Sample } & \multicolumn{3}{|c|}{ Area } & \multicolumn{4}{|c|}{ Percentage } \\
\hline & Noneluted & Eluted & Total & Noneluted & Eluted & $\begin{array}{l}\text { LA/UV } \\
\text { Noneluted }\end{array}$ & $\begin{array}{l}\text { LA/UV } \\
\text { Eluted }\end{array}$ \\
\hline \multicolumn{8}{|l|}{ UV } \\
\hline A 2017 & 1,311 & 588 & 2,556 & 77 & 23 & & \\
\hline HMW & 1,152 & 232 & 1,354 & 83 & 17 & & \\
\hline MMW & 2,113 & 704 & 2,814 & 75 & 25 & & \\
\hline LMW & 1,446 & 754 & 2,200 & 66 & 34 & & \\
\hline $\mathrm{T}$ & 1,654 & 966 & 2,540 & 63 & 37 & & \\
\hline Porphyrins & 5 & 395 & 400 & 1 & 99 & & \\
\hline \multicolumn{8}{|l|}{ LA-ICP-MS } \\
\hline A 2017 & $3,317,643$ & 469,063 & $3,786,707$ & 88 & 12 & 2530 & 1.91 \\
\hline HMW & 692,888 & 63,514 & 756,402 & 92 & 8 & 601 & 2.13 \\
\hline MMW & $1,609,144$ & 609,555 & $2,218,699$ & 73 & 27 & 762 & 0.93 \\
\hline LMW & 900,274 & 482,428 & $1,382,702$ & 65 & 35 & 623 & 0.97 \\
\hline $\mathrm{T}$ & 839,530 & 297,053 & $1,136,583$ & 74 & 26 & 508 & 1.54 \\
\hline Porphyrins & $13,610,088$ & $209,863,919$ & $223,474,007$ & 6 & 94 & $2,722,018$ & 531,301 \\
\hline
\end{tabular}


Table 5. Average of the Areas and Percentages of Noneluted and Eluted Material from $5 \mu \mathrm{g}$ of Each Asphaltene Sample on Three Different Plates for UV and ${ }^{51}$ V by LA-ICP-MS After Image Processing

\begin{tabular}{|c|c|c|c|c|c|c|c|}
\hline & \multicolumn{3}{|c|}{ Area } & \multicolumn{4}{|c|}{ Percentage } \\
\hline Sample & Noneluted & Eluted & Total & Noneluted & Eluted & $\begin{array}{l}\text { Ratio } \\
\text { LA/UV } \\
\text { Noneluted }\end{array}$ & $\begin{array}{l}\text { Ratio } \\
\text { LA/UV } \\
\text { Eluted }\end{array}$ \\
\hline \multicolumn{8}{|l|}{ UV } \\
\hline A 2017 & 3,926 & 954 & 4,880 & 80 & 20 & & \\
\hline $\mathrm{AC} 7$ & 3,875 & 935 & 4,810 & 81 & 19 & & \\
\hline AC 5 & 3,644 & 1,175 & 4,819 & 76 & 24 & & \\
\hline Porphyrins & 5 & 395 & 400 & 1 & 99 & & \\
\hline \multicolumn{8}{|l|}{ LA-ICP-MS } \\
\hline A 2017 & $7,307,202$ & 918,289 & $8,225,490$ & 89 & 11 & 1861 & 963 \\
\hline $\mathrm{AC} 7$ & $6,878,423$ & 433,202 & $7,311,625$ & 94 & 6 & 1775 & 463 \\
\hline AC 5 & $4,932,036$ & 581,532 & $5,513,568$ & 89 & 11 & 1353 & 495 \\
\hline Porphyrins & $13,610,088$ & $209,863,919$ & $223,474,007$ & 6 & 94 & $2,722,018$ & 531,301 \\
\hline
\end{tabular}




\section{FIGURES}

Figure 1. (a) ${ }^{51} \mathrm{~V}$ signal and (b) ${ }^{58} \mathrm{Ni}$ signal from LA-ICP-MS of a 1-step $(40 \mathrm{~mm})$ development with silica (red line) and cellulose (Black line) HPTLC plates with DCM/MeOH 99.5/0.5\%v of $1 \mu \mathrm{g}$ of the reference porphyrin mixture. 
Figure 2. Densitometry UV spectrum of the (black line) eluted and (red line) noneluted fractions of the reference porphyrin mixture on cellulose (a) and silica (b) HPTLC plates. UV at $280 \mathrm{~nm}$ (red line) and ${ }^{51} \mathrm{~V}$ signal (black line) from LA-ICP-MS of the reference porphyrin mixture on cellulose (c) and silica (d) HPTLC plates. 
Figure 3. (a) Picture at $280 \mathrm{~nm}$ of the cellulose plate after separation of the vanadyl porphyrins. (b) Six-point calibration curve obtained with vanadyl porphyrin by LA-ICP-MS after image processing. 
Figure 4. Chromatogram of vanadium in Asphaltene 2017 from GPC-ICP-MS (black line) and vanadyl porphyrin (dotted line). Fraction limits were set at 39-49 min for HMW, 49-60 min for MMW, 60-70 min for LMW and 71-91 min for Tailing based on the trimodal distribution seen in chromatograms of $\mathrm{V}$-containing aggregates. 
Figure 5. (a) Picture at $280 \mathrm{~nm}$ of the cellulose plate after migration. (b) LA-ICP-MS

chromatograms (black line) and UV spectra (red line) of the 1-step (30 mm) development on cellulose HPTLC plates with DCM/MeOH of $1 \mu \mathrm{g}$ of the preparative GPC fractions of Asphaltene 2017. 
Figure 6. UV spectra of $1 \mu \mathrm{g}$ of each preparative GPC fraction, HMW, MMW, LMW and T, of Asphaltene 2017 and the total Asphaltene 2017. Dotted lines represent the vanadyl porphyrin. Vertical lines represent a change in the lamp setting on the device. The Soret band corresponding to free porphyrins is indicated with a star. 
Figure 7. LA-ICP-MS chromatograms of the 1-step (40 mm) development on cellulose HPTLC plates with DCM/MeOH of $1 \mu \mathrm{g}$ of Asphaltene 2017 (a), Asphaltene C7 (b) and Asphaltene C5 (c). 